\title{
Application of Interval Fuzzy Multi - objective Strategy Model in Water Resources Optimal Allocation
}

\author{
Min Zhu \\ Pingxiang University, Pingxiang, Jiangxi, 337055, China
}

Keywords: Water Resources; Optimal Allocation; Multi-objective Strategy Model; Non-linear programming

\begin{abstract}
Fuzzy multi-objective programming is an important optimization method to solve many complex practical problems. In this work, the applications of fuzzy multi-objective programming modeling for solving the practical problems in regional water resources optimal scheduling are studied. In order to strengthen the planning and management of water resources, the limited water resources are fully and effectively used scientifically. And because of the multi-objective and uncertainties of the regional water resources optimization scheduling problem, this paper adopts the fuzzy multi-objective programming method to deal with this complex practical problem. Based on the fuzzy multi-objective programming technique, the fuzzy multi-objective nonlinear programming model of regional water resources optimal dispatching is established. The multi-objective includes three goals: economic benefit, environmental benefit and social benefit. Then, the establishment and solving steps of the fuzzy multi-objective nonlinear programming model are introduced for the established model. Finally, the proposed scheme is evaluated and sorted. Finally, combined with the actual situation of a city to solve, verify the validity of the model.
\end{abstract}

\section{Introduction}

Regional water resources optimization scheduling problem is such a complex practical problem: in the watershed or a specific area, follow the effectiveness, fairness and sustainability and other principles, the use of various engineering and non-engineering measures, in accordance with the market economic rules and resource allocation guidelines, through the reasonable suppression of demand, to ensure the effective supply, maintenance and improvement of the quality of the ecological environment and other means and measures for a variety of available water sources in the regional water supply between the various departments. And in the current situation, due to the shortage of water resources, regional economic development and population growth, the increasing demand for water, the continuous improvement of regional water resources development and utilization, regional water supply and demand is increasing, so coordination within the system regional, various departments, the contradictions between the various sectors of the water, to study the whole system to meet the economic, social and environmental benefits of the best benefits under the premise of the water supply departments, so that limited water resources to maximize the benefits, and can provide sustainable development momentum for this region, which has important practical significance. Due to the multi-objective and ambiguity of regional water resources optimal scheduling problem and the superiority of fuzzy multi-objective programming in dealing with such problems, the two aspects will be combined to improve the practicality of regional optimal allocation of water resources and scientific nature ${ }^{[1-2]}$.

In the existing water resources optimization model, there are several problems as follows: first, the target is single, and most of them are the economic efficiency maximization model. taking into account the economic, environmental, social and other goals of the model is relatively small. Second, even if the majority of the multi-objective model is also a deterministic model, the fuzzy factors in the optimal allocation of water resources are not taken into account. In terms of model solving, the method of solving single target is relatively mature, but the research method of multi-objective is relatively few. Based on the above-mentioned problems, a fuzzy multi-objective programming model of regional water resources optimal scheduling is proposed, which includes fuzzy linear multi-objective programming model of regional water resources and fuzzy multi-objective 
programming model of regional water resources. Compared with deterministic planning, fuzzy target planning does not need to determine the exact expectations of the target, only need to determine the target fuzzy expectations, that is, a range of values, which is clearly more in line with the actual situation ${ }^{[3-6]}$.

\section{Overview of Fuzzy Optimization}

The purpose of finding optimizing design is often the pursuit of maximum yield, lightest weight or other performance indicators to establish the "objective function": $y=f(x)$. The "excellent" and "inferior" of the scheme itself is a vague concept, there is no clear boundaries and clear standards, especially for multi-objective problems, often only the pursuit of "satisfactory solution", and solution itself is uncertain. Not all programs in the design are feasible, must meet the conditions $g(x) \leq 0$ specified in the design specifications and standards, which is called a constraint. These constraints often contain a lot of fuzzy factors. In general, the above problem is to solve the conditional extremum of the objective function under fuzzy constraints.

Trappey et al. first studies the fuzzy nonlinear programming (FNLP) problem, and uses the linear membership function to describe the fuzzy target and constraint of the system. Ali et al. proposed to use the differential equation method to solve the nonlinear programming problem with fuzzy parameters. Tang Jiafu et al. discussed the quadratic programming problem and the nonlinear programming problem with fuzzy objective and fuzzy resource constraints. The basic idea is to find a neighborhood of the optimal solution, so that each solution in the neighborhood is the solution that the decision maker can accept, that is, the optimal solution in the fuzzy environment. And proposes an interactive method to obtain the fuzzy optimal solution needed by the decision maker, so that the decision maker can make different decisions under different criteria ${ }^{[7-9]}$.

\section{The establishment and solution of the model}

The regional optimal allocation model of water resources is a fuzzy multi-objective non-linear programming model. By solving this model, we can get the optimal allocation of water resources under the coordinated and healthy development of this system, including the economic objectives, environmental objectives and social objectives of the three objectives ${ }^{[10]}$.

(1) Economic Objectives: The economic benefit of water use in different industries in each sub-district is the largest.

$$
\operatorname{Max} \tilde{f}_{1}(x)=\sum_{k} \sum_{j}\left[\sum_{i}\left(b_{i j}^{k}-a_{i j}^{k}\right) x_{i j}^{k}+\sum_{p}\left(b_{p j}^{k}-a_{p j}^{k}\right) x_{p j}^{k}\right] \tilde{z} z_{1 g}
$$

$f_{1}(x)$ is the economic net benefit objective function for regional water supply, and $x$ is the decision variable.

(2)Environmental objectives: The minimum level of COD emissions in each sub-district.

$$
\min \tilde{f}_{2}(x)=\sum_{k} \sum_{j}\left(\sum_{i} P_{i j}^{k} x_{i j}^{k}+\sum_{p} P_{i j}^{k} x_{i j}^{k}\right) \tilde{\leq} z_{2 g}
$$

$f_{2}(x)$ is regional target for significant pollutant emissions.

(3)Social goals: Residents living water consumption at the least deviation.

$$
\min \tilde{f}_{3}(x)=\sum_{k}\left[D_{j}^{k}-\left(\sum_{i} x_{i j}^{k}+\sum_{i} x_{p j}^{k}\right)\right] \tilde{\leq} z_{3 g}
$$

$f_{3}(x)$ is water shortage of water supply and demand system

Constraints for the above objective functions:

Supply constraints independent water: $\quad \sum_{k} x_{i j}^{k} \leq W_{i}$

Supply constraints of public water:

$$
\sum_{k} \sum_{j} x_{p j}^{k} \leq W_{p}
$$


Non-negative constraint:

$$
\begin{aligned}
& x_{i j}^{k} \geq 0 \\
& \sqrt{u_{1} u_{2}} \geq 0.08
\end{aligned}
$$

Coordinated development constraints:
Based on the genetic algorithm to obtain the fuzzy optimal solution, the general fuzzy target and fuzzy resource constrained nonlinear programming has the following form:

$$
\begin{gathered}
\max f(x)=f\left(x_{1}, x_{1}, \ldots \ldots x_{n}\right) \\
g(x) \leq b
\end{gathered}
$$

Where $g(x)$ is function vector of constraint.

Based on the genetic algorithm, the fuzzy optimal solution is not to find a precise optimal solution, but to find the neighborhood of an optimal solution, so that each solution in the neighborhood is the solution that the decision maker needs and the optimal solution of the decision maker in the fuzzy environment. The basic idea is to first determine an acceptable fuzzy optimal membership by the decision maker. Randomly generate a population of NP (population size) individuals, each individual according to the size of its adaptive function to move in the direction of increasing (to produce sub-individual), for membership less than $a_{0}$ sub-individual, the small membership is such that the chance of being smaller in the iterations of the subsequent sub-individual than the child of the higher membership is selected to produce the child. In this way, the sub-individuals whose membership is less than $a_{0}$ are gradually eliminated and are sub-individuals with large membership. So after a certain number of iterations, each individual is the solution that the decision maker wants ${ }^{[11-12]}$.

Genetic algorithm steps is shown in Figure 1:

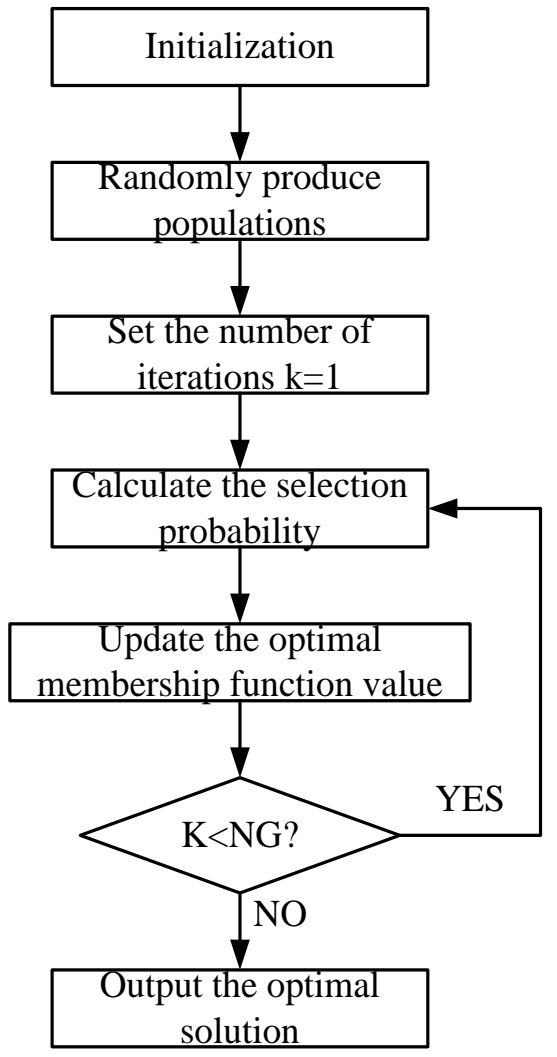

Figure 1. The calculation steps of the genetic algorithm

\section{Verification of examples}

Take A city as an example, the COD emissions in 2010 of the base year are 36 thousand and 900 tons, and the per capita GDP is 15326 yuan. Other parameters are entered, and the target parameters are as follows:

The water supply guarantee rate is $90 \%$, and the target upper and lower limits are as follows: 
Tab.1 The target upper and lower limits when the water supply guarantee rate is $90 \%$

\begin{tabular}{|c|c|c|c|}
\hline Parameter class & Parameter meaning & Parameter value & Unit \\
\hline \multirow{4}{*}{ Target expectation } & Total economic goals & 16.06 & Million yuan \\
\cline { 2 - 4 } & $\begin{array}{c}\text { Total environmental } \\
\text { objectives }\end{array}$ & 32555 & Cubic meter \\
\cline { 2 - 4 } & Total social goals & 0 & Million yuan \\
\hline \multirow{4}{*}{$\begin{array}{c}\text { Upper and lower limits of limit of total } \\
\text { Target }\end{array}$} & $\begin{array}{c}\text { Uppen limit of total } \\
\text { economic target }\end{array}$ & 13.2 & Ton \\
\cline { 2 - 4 } & $\begin{array}{c}\text { Total social objective } \\
\text { ceiling }\end{array}$ & 36000 & Cubic meter \\
\cline { 2 - 4 }
\end{tabular}

Using genetic algorithm, the water supply guarantee rate is $90 \%$, and the results of each target are shown in Tab.2 :

Tab.2 The optimal solution of the target when Comprehensive optimum when the water supply guarantee rate is $90 \%$

\begin{tabular}{|c|c|c|c|}
\hline Project & $\begin{array}{c}\text { Economic goal(Million } \\
\text { yuan) }\end{array}$ & $\begin{array}{c}\text { Environmental } \\
\text { objective (Ton) }\end{array}$ & $\begin{array}{c}\text { Social goal(Cubic } \\
\text { meter) }\end{array}$ \\
\hline $\begin{array}{c}\text { Comprehensive } \\
\text { optimum }\end{array}$ & 14.934 & 33910 & 335000000 \\
\hline Social goal is optimal & 14.46 & 33490 & 7000000 \\
\hline $\begin{array}{c}\text { Economic goal is } \\
\text { optimal }\end{array}$ & 15.31 & 34790 & 595000000 \\
\hline $\begin{array}{c}\text { Environmental } \\
\text { objective is optimal }\end{array}$ & 14.391 & 32750 & 595000000 \\
\hline
\end{tabular}

When the water supply guarantee rate is $90 \%$, the optimal combination of water resources in different regions is shown in Tab.3

Tab.3 Optimal operation results of water resources when Comprehensive optimum

\begin{tabular}{|c|c|c|r|r|r|r|}
\hline \multirow{2}{*}{ Region } & $\begin{array}{c}\text { Source of } \\
\text { water }\end{array}$ & $\begin{array}{c}\text { Industrial } \\
\text { water(Ton) }\end{array}$ & $\begin{array}{r}\text { Agricultur } \\
\text { al water(Ton) }\end{array}$ & $\begin{array}{c}\text { Urban } \\
\text { water(Ton) }\end{array}$ & $\begin{array}{c}\text { Rural } \\
\text { water(Ton) }\end{array}$ & $\begin{array}{c}\text { Ecological } \\
\text { water(Ton) }\end{array}$ \\
\hline \multirow{2}{*}{ Area A } & $\begin{array}{c}\text { Surface } \\
\text { water }\end{array}$ & 8230000 & 8620000 & 1840000 & 1210000 & 790000 \\
\cline { 2 - 7 } & $\begin{array}{c}\text { groundwat } \\
\text { er }\end{array}$ & 16860000 & 45170000 & 31500000 & 2190000 & 5210000 \\
\hline \multirow{2}{*}{ Area B } & $\begin{array}{c}\text { Surface } \\
\text { water }\end{array}$ & 4550000 & 6130000 & 2010000 & 550000 & 160000 \\
\cline { 2 - 7 } & $\begin{array}{c}\text { groundwat } \\
\text { er }\end{array}$ & 9690000 & 99920000 & 7340000 & 1150000 & 740000 \\
\hline \multirow{2}{*}{ Area C } & $\begin{array}{c}\text { Surface } \\
\text { water }\end{array}$ & 7040000 & 7800000 & 1560000 & 1090000 & 10000 \\
\cline { 2 - 7 } & $\begin{array}{c}\text { groundwat } \\
\text { er }\end{array}$ & 30560000 & 81360000 & 3960000 & 1910000 & 3030000 \\
\hline \multirow{2}{*}{ Area D } & $\begin{array}{c}\text { Surface } \\
\text { water }\end{array}$ & 7270000 & 7440000 & 1460000 & 1710000 & 780000 \\
\cline { 2 - 7 } & $\begin{array}{c}\text { groundwat } \\
\text { er }\end{array}$ & 20510000 & $\begin{array}{c}20519000 \\
0\end{array}$ & 3460000 & 4090000 & 5220000 \\
\hline
\end{tabular}

From the results of fuzzy multi-objective nonlinear programming of regional water resources, it can be seen that the planning results are reasonable. Compared with the fuzzy multi-objective linear programming of water resources, the non-linear model not only fully considers the relationship between social, economic and environmental objectives, but also the social and economic environmental and environmental objectives of the system to achieve the coordinated development and sustainable development, so the establishment of fuzzy multi-objective water resources planning is more realistic. 


\section{Summary}

Based on the maximum benefit of economy, environment and society, this work establishes a multi-objective non-linear programming model for regional optimal allocation of water resources. The non-linear model takes full account of the relationship between social, economic and environmental objectives, also considering the factors of sustainable development, so that the overall benefits become maximize Through the case verification of A city, the genetic algorithm is used to solve the problem, and a comprehensive optimal solution is obtained to prove that the fuzzy multi-objective non-linear programming model of water resources is more realistic.

\section{References}

[1] Prasad T D, Park N S. Multiobjective genetic algorithms for design of water distribution networks[J]. Journal of Water Resources Planning and Management, 2004, 130(1): 73-82.

[2] Burn D H, Yulianti J S. Waste-load allocation using genetic algorithms[J]. Journal of Water Resources Planning and Management, 2001, 127(2): 121-129.

[3] Yeh W W G, Becker L. Multiobjective analysis of multireservoir operations[J]. Water resources research, 1982, 18(5): 1326-1336.

[4] Prasad T D, Walters G A, Savic D A. Booster disinfection of water supply networks: Multiobjective approach[J]. Journal of Water Resources Planning and Management, 2004, 130(5): 367-376.

[5] Liebman J C, Lynn W R. The optimal allocation of stream dissolved oxygen[J]. Water Resources Research, 1966, 2(3): 581-591.

[6] Han Y, Huang Y F, Wang G Q, et al. A multi-objective linear programming model with interval parameters for water resources allocation in Dalian city[J]. Water resources management, 2011, 25(2): 449-463.

[7] Zitzler E, Deb K, Thiele L. Comparison of multiobjective evolutionary algorithms: Empirical results[J]. Evolutionary computation, 2000, 8(2): 173-195.

[8] Amini Fasakhodi A, Nouri S H, Amini M. Water resources sustainability and optimal cropping pattern in farming systems; a multi-objective fractional goal programming approach[J]. Water resources management, 2010, 24(15): 4639-4657.

[9] Wardlaw R, Sharif M. Evaluation of genetic algorithms for optimal reservoir system operation[J]. Journal of water resources planning and management, 1999, 125(1): 25-33.

[10]Liu D, Chen X, Lou Z. A model for the optimal allocation of water resources in a saltwater intrusion area: a case study in Pearl River Delta in China[J]. Water resources management, 2010, 24(1): 63-81.

[11]Liu D, Guo S, Chen X, et al. A macro-evolutionary multi-objective immune algorithm with application to optimal allocation of water resources in Dongjiang River basins, South China[J]. Stochastic environmental research and risk assessment, 2012, 26(4): 491-507.

[12]Li Y P, Huang G H, Nie S L. An interval-parameter multi-stage stochastic programming model for water resources management under uncertainty[J]. Advances in Water Resources, 2006, 29(5): 776-789. 